\title{
Greetings from the new Editor-in-Chief of the Journal of Plant Research 2021
}

\author{
Maki Katsuhara ${ }^{1}$
}

Published online: 15 April 2021

(c) The Botanical Society of Japan 2021

It is my pleasure to be writing this editorial as Editor-in-Chief of the Journal of Plant Research (JPR) for the next 4 years, following the former Editor-in-Chief, Prof. Kouki Hikosaka of Tohoku University. I will do my best to improve JPR along with all editors, board members, and readers.

As previous described (Hikosaka 2017), we are proud that world famous findings on the sperm of Ginkgo biloba L. (Hirase 1896) and Cycas revoluta Thunb. (Ikeno 1896) were published in Shokubutsugaku Zasshi (The Botanical Magazine, Tokyo), the predecessor of JPR. The name of the journal was changed to the present Journal of Plant Research in 1993, and online publication launched in 2003. JPR is continuously growing, and its Impact Factor is 2.185 in 2019. $J P R$ is recognized as a Q1 journal (2019) in the Plant Science category. JPR received 961 submissions last year, and, as an international journal, $94 \%$ submitted manuscripts were from outside of Japan. Unfortunately, we cannot accept many of these manuscripts due to our page limitation.

$J P R$ is dedicated to the dissemination of fundamental knowledge in all areas of basic plant sciences. This journal's wide scope is unique nowadays, as scientific interests and many journals' scopes tend to be specialized and narrow. However, we believe that $J P R$ can strongly contribute to developing new and interdisciplinary areas of basic plant biology. Current techniques and technology actually accelerate the fusion of areas, and JPR encourages the publication of such articles, for example, papers in the present $J P R$ symposium "Beyond fibonacci patterns and the golden angle: phyllotactic variations and their cellular origin" (see below pages in this issue) and the last JPR symposium "Toward an understanding of nuclear substructures beyond their classical functions" (Sakamoto and Sakamoto 2020).

In recent years, research integrity has become more and more important. JPR supports and promotes this trend. Research integrity contains many aspects, but when it comes

Maki Katsuhara

jpreic@okayama-u.ac.jp

1 Institute of Plant Science and Resources, Okayama

University, Kurashiki 710-0046, Japan to publishing, falsification is, of course, strictly prohibited. Double/multiple submissions and plagiarism are automatically monitored at the submission stage, including those covering the author's own work, and suspicious submissions are immediately refused by JPR. Preprints and doctoral theses are not included in double submissions, but their status must be clearly stated in the manuscript. These research misconducts are not the end-all and be-all of research integrity. We will strive to ensure that the following positive aspects of research integrity are enforced: objectivity of research, honesty of researchers, fairness of peer review and evaluation of previous research, legitimate authorship, etc.

Along with research integrity, JPR is also committed to promoting publication innovation. Improving the efficiency of the submission and peer review system, and speeding up the publication process will be necessary for JPR to be more widely accepted and appreciated by authors and readers in the future. This will not be easy to achieve, but JPR will work on innovation step by step. For example, a more author-friendly submission style/system should be considered.

I would like to express my appreciation for this year's editors; Drs. Koji Takayama, Juan Núñez-farfán, Yanhong Tang, Atushi Ushimaru, Haruhiko Taneda, Akitoshi Iwamoto, Ali Ferjani, Kimitsune Ishizaki, Jutta Papenbrock, Shigemi Seo, Michael Wrzaczek, Koichiro Awai, Yoshitaka Nishiyama, Misato Ohtani, Kohki Yoshimoto. They really contribute to JPR by handling a large number of manuscripts. Some of them started their works since last January as Prof. Hikosaka (2021) reported. I also give much thanks to the Advisory Board members, and Editorial Board members. I also greatly appreciate the secretary work of Dr. Masako Mishio, and English proofing by Mr. Miles Peterson. JPR is supported by these members and will continuously publish the fruits of plant sciences. 


\section{References}

Hikosaka K (2017) Greetings from the new Editor-in-Chief. J Plant Res 130:417-418

Hikosaka K (2021) With gratitude from the Editor-in-Chief of the Journal of Plant Research. J Plant Res 134:1-2

Hirase S (1896) Ichou-no-seishi-ni-tsuite (in Japanese) (On the spermatozoid of Ginkgo biloba). Shokubutsugaku-Zasshi (Bot Mag) $10: 325-328$
Ikeno S (1896) Sotetsu-no-seichu (in Japanese) (Spermatozoid of Cycas revoluta). Shokubutsugaku-Zasshi (Bot Mag) 10:367-377

Sakamoto Y, Sakamoto T (2020) Toward an understanding of nuclear substructures beyond their classical functions. J Plant Res 133:447-448

Publisher's Note Springer Nature remains neutral with regard to jurisdictional claims in published maps and institutional affiliations. 